Forum 2018 $\cdot 33: 54$

https://doi.org/10.1007/s12312-017-0379-7

Online publiziert: 9. Januar 2018

○) Springer Medizin Verlag GmbH, ein Teil von Springer Nature 2018

Arbeitsgemeinschaft Prävention und integrative Onkologie (PRIO)

\title{
Zertifikat Integrative Onkologie der Arbeitsgemeinschaft PRIO geht in die nächste Runde
}

sen brisanten Themen stellt sich der neue Arbeitskreis Spiritualität vor: ein Drittel der Patienten mit einer malignen Erkrankung in Deutschland gibt Gebete als wichtige Ressource an - was steckt dahinter und wie gehen wir damit um?

\section{Datum:}

20.-21.04.2018

Ort:

Räume der Deutschen Krebsgesellschaft, Berlin

Nähere Informationen:

www.prio-dkg.de

Rückfragen an:

Prof. Dr. Jutta Hübner

Vorsitzende der AG PRIO

jutta.huebner@med.uni-jena.de
Anmeldungen an:

Frau Tänzer, Universitätsklinikum Jena, Medizinische Klinik II, simone.taenzer2@ med.uni-jena.de

Die Seminarreihe der AG PRIO geht weiter im Herbst mit dem Thema Ernährung in der Onkologie am 12.-13.10.2018 in Wiesbaden.

\section{Korrespondenzadresse}

\section{Prof. Dr. Jutta Hübner}

Abt. Hämatologie und Intern. Onkologie

Klinik für Innere Medizin II

Am Klinikum 1

07747 Jena

Tel.: 03641/9324256

jutta.huebner@med.uni-jena.de 